\title{
A PLACE-BASED POLICY FOR PROMOTING INDUSTRY 4.0: THE CASE OF THE CASTELLON CERAMIC TILE DISTRICT
}

Hervas Oliver, Jose Luis; Estellés Miguel, Sofía; Mallol Gasch, Gustavo; Boix Palomero, Juan.

\begin{abstract}
Digitization and its impact on regions and clusters remains overlooked in the literature, and constitute this present paper's goal. How does an industrial district transit collectively to the adoption of new radical changes brought about by Industry 4.0? This study explores the role of collective actors and innovation platforms during the early stages of a pilot policy to stimulate a collective transition of an entire MID (Marshallian Industrial District) into Industry 4.0. We posit that institutional isomorphism and the existent social capital in MIDs is a double-sword phenomenon that can also positively constitute an enabler for fostering change on a collective-basis. Technology transitions, such as Industry 4.0, can be supported and led by collective actors that are central in facilitating the adoption of Industry 4.0 in MIDs, enticing innovative firms to engage in that transition, establishing, legitimizing, and embedding a new set of processes, practices and inter-firm arrangements for digitizing and then promoting imitation: the positive leverage of isomorphism. Thus, MID transition is facilitated through capitalizing on the MID logic of cooperation-competition and isomorphism, by developing and promoting a collective understanding of the new paradigm, building a supportive infrastructure, educating in the new technology and avoiding cognitive inertia.
\end{abstract}

\section{KEYWORDS}

Clusters; Industry 4.0; Innovation; Marshallian Industrial Districts 